(FL): StatPearls Publishing. Copyright (C) 2021, StatPearls Publishing LLC.; 2021.

2. Boev C, Kiss E. Hospital-Acquired Infections: Current Trends and Prevention. Critical care nursing clinics of North America. 2017;29(1):51-65.

3. Asfaw N. Knowledge and practice of nurses towards prevention of hospital acquired infections and its associated factors. International Journal of Africa Nursing Sciences. 2021;15:100333.

4. Bayleyegn B, Mehari A, Damtie D, Negash M. Knowledge, Attitude and Practice on HospitalAcquired Infection Prevention and Associated Factors Among Healthcare Workers at University of Gondar Comprehensive Specialized Hospital, Northwest Ethiopia. Infection and drug resistance. 2021; 14:259-66.
5. Organization WH. Guidelines on core components of infection prevention and control programmes at the national and acute health care facility level. Geneva: World Health Organization; 2016.

6. Organization WH. Infection prevention and control assessment framework at the facility level. World Health Organization; 2018.

7. Organizationx WH. World Health Organization Guidelines on Hand Hygiene in Health Care 2009 [Available from: www.who.int/ gpsc/5may/tools/ 9789241597906/en/

8. Mathai E, Allegranzi B, Kilpatrick C, Bagheri Nejad S, Graafmans W, Pittet D. Promoting hand hygiene in healthcare through national/subnational campaigns. The Journal of hospital infection. $2011 ; 77(4): 294-8$.

\title{
ĐĂC ĐIỂM LÂM SÀNG, CÂ̂N LÂM SÀNG BÊNNH NHÂN XEP ĐA TẦNG CộT SỐNG NGỰC VÀ THẮT LƯNG DO LOÃNG XƯƠNG ĐIỀU TRI BẰNG PHƯƠNG PHÁP BƠM CEMENT SINH HỌC
}

\section{Trịnh Bá Thắng*, Hoàng Gia Du*, Nguyễn Văn Trung*, Vũ Xuân Phước*, Nguyễn Đức Hoàng*, Lê Đăng Tân*, Trịnh Minh Đức*, Phan Bá Quỳnh*. \\ SUBCLINICAL FEATURES}

\section{TÓM TẮT}

Mục đích: Mô tả đặc điểm lâm sàng, cân lâm sàng của các bệnh nhân xẹp đa tâng cột sống ngực, thắt lưng được điều trị bằng phương pháp bớm cement sinh học. Phương pháp nghiên cứu: Mô tả cắt ngang 28 trường hợp xẹp đa tầng cột sống ngực thắt lưng được điêu trị bằng phương pháp bơm cement sinh học đa tầng tại Bệnh viện Bạch Mai từ tháng 01 năm 2019 đến tháng 6 năm 2021. Kết quả: Tỷ lệ nữ/ nam: 8.35, tuổi trung bình 70.5 tuổi (44-86), $100 \%$ bênh nhân có bênh nền. Triêu chứng chính: đau đột ngột tại cột sống do chấn thương nhẹ hoặc tự nhiên kèm hạn chế vận động do đau, VAS trung bình 7.04 điểm (6-9), tổng số 103 đốt xẹp mới, vị trí tổn thương nhiều nhất ở $\mathrm{T}_{12}$ (17 đốt xẹp), chủ yếu là xep hình chêm (51.5\%), 75\% bệnh nhẩn có biến dạng cột sống- T-Score trung bình -3.89. Kết luân: Xep đa tầng cột sống ngực thắt lưng do loãng xưởng chủ yếu ở bệnh nhân cao tuổi, nữ giới, có bệnh lý nền, khởi phát sau một chấn thương nhẹ hoặc tự nhiên, thường đau kéo dài, tỷ lệ biến dạng cột sống cao, mức độ loãng xương nặng.

Tư Khóa: xẹp đa tầng cột sống, lâm sàng và cận lâm sàng.

\section{SUMMARY}

MULTILEVEL VERTEBROPLASTY: CLINICAL,

*Bênh viên Bach Mai.

Chịu trách nhiệm chính: Trịnh Bá Thắng

Email: dr.trinhbathang2502@gmail.com

Ngày nhận bài: 10.9.2021

Ngày phản biên khoa hoc: 28.10.2021

Ngày duyệt bài: 11.11.2021
Objectives: Analyzing clinical, subclinical features of the patients was diagnosed osteoporosis multilevel vertebral compression fractures (OMVCFs) was treated by percutaneous vertebroplasty (VP). Methods: Cross- sectional descriptive retrospective and prospective study of 28 OMVCFs underwent VP in Bach Mai hospital from 1/2019 to 6/2021. Result: The female-male ratio is 8.35 with mean age of 70.5 (4486 years old), all of the patients have background, the patients frequently presented with sudden onset of pain in proportion to VCFs because of light trauma or natural happening with decreasing of spinal mobility because of pain, the mean of VAS score is $7.04, T_{12}$ is the most in 103 new injuried segments (17 segments), fracture type: wedge fratures is the highest ratio $(51,5 \%)$, the spinal deformity ratio is $75 \%$, mean TScore is -3.89 . Conclusion: Osteoporosis multilvel vertebral compression fracture freaquently present in elder woman underwent a light injury or have not reason, frequently prolonged pain and severe osteoporosis. The deformity ratio and background disease ratio is high.

Key words: multilevel vertebral compression fractures, clinical and subclinical features.

\section{I. ĐĂT VẤN ĐỀ}

Xẹp thân đốt sống (XTĐS) là bệnh lý gây giảm chiều cao cột sống kèm theo đau lưng dai dẳng ${ }^{1}$. Ngày nay, cùng với sự phát triển xã hội, xẹp thân đốt sống xảy ra ngày càng phổ biến. Có khoảng 1.5 triệu trường hợp XTĐS xảy ra mỗi năm ở Mỹ, thường xảy ra phổ biến ở nhóm người cao tuổi, khoảng $25 \%$ trong tổng số phụ nữ sau 
mãn kinh xuất hiện XTĐS, Tỷ lệ XTĐS tăng lên tỷ lệ thuận với độ tuổi, tỷ lệ này ở độ tuổi 80 khoảng $40 \%^{2}$. Bệnh lý XTĐS do loãng xương xảy ra thường sau chấn thương nhe hoăc có thể đôt ngột không liên quan đến chấn thương. Triệu chứng lâm sàng chính là đau tại cột sống, tăng lên khi vận động, giảm khi nghỉ ngơi, hạn chế vân động do đau, trường hợp nă̆ng có thể gây biến dạng cột sống ${ }^{2}$. Xẹp thân đốt sống không chỉ xảy ra ở 1 hay 2 đốt sống mà còn có thể xẹp trên nhiều thân đốt sống (xẹp đa tầng thân đốt sống từ 3 đốt sống trở lên) (XĐTTĐS). Xepp đa tầng thân đốt sống có nguy cơ cao dẫn tới biến dang cột sống ${ }^{2}$, gây đau mạn tính kém đáp ứng với thuốc giảm đau, các rối loạn về hô hấp, tiêu hóa nếu không được điều trị kịp thờ ${ }^{1}{ }^{1}$, xquang đơn thuần không đánh giá đầy đủ tổn thương đốt sống, cần sự hỗ trợ của cắt lớp vi tính và cộng hưởng từ. Tạo hình thân đốt sống bằng bơm cement sinh học (BCSH) qua cuống là can thiệp ít xâm lấn được sử dụng phổ biến, có hiệu quả tốt trong điêu trị xẹp XTĐS do loãng xương ${ }^{3}$. Tại khoa Chấn thương chỉnh hình và cột sống Bệnh viện Bạch Mai, chúng tôi đã tiến hành bơm cement cho nhiều bênh nhân xẹp đa tầng cột sống và cho thấy kết quả khả quan. Trên cơ sở đó chúng tôi tiến hành nghiên cứu nhằm đánh giá những đặc điểm lâm sàng và cận lâm sàng của những bệnh nhân này.

\section{II. ĐỐI TƯƠNG VÀ PHƯƠNG PHÁP NGHIÊN CỨU}

2.1. Đối tượng nghiên cứu. Nghiên cứu 28 bệnh nhân chẩn đoán xẹp đa tầng cột sống ngực - thắt lưng do loãng xương được tạo hình thẩn đốt sống bằng bơm cement sinh học qua cuống (từ 3 đốt sống trở lên) tại khoa Chấn thương chỉnh hình và cột sống bệnh viện Bạch Mai từ tháng 1 năm 2019 đến tháng 6 nằm 2021.

2.2. Tiêu chuẩn lựa chọn. Tất các bệnh nhân chẩn đoán xẹp đa tầng cột sống ngực thắt lưng được phẫu thuật tạo hình thân đốt sống đa tầng bằng bơm cement sinh học, đồng ý tham gia nghiên cứu và có hồ sơ bệnh án đây đủ.

2.3. Tiêu chuẩn loai trừ. Bênh nhân không đồng ý tham gia nghiên cứu, hồ sơ bệnh án không đầy đủ thông tin.

2.4. Phương pháp nghiên cứu. Phương pháp nghiên cứu mô tả cắt ngang. Chọn mẫu thuận tiện, lựa chọn tất cả các trường hợp đủ tiêu chuẩn nghiên cứu trong thời gian nghiên cứu.

\subsection{Các biến nghiên cứu.}

Lâm sàng: Tuổi (phân loại tuổi theo Cooper), giới, tiền sử bệnh nền, nguyên nhân loãng xương (nguyên phát, thứ phát), hoàn cảnh khởi phát (sau chấn thương, tự nhiên), thời gian diễn biến bệnh (dưới 30 ngày, 31-60 ngày, 61-90 ngày, trên 90 ngày), tính chất khởi phát (đột ngột, từ từ), điểm VAS, hạn chế vận động (theo các mức độ: hạn chế đi lại, không ngồi được, không đi lại được), hạn chế hô hấp (khó thở, viêm phổi liên quan XTĐS), đáp ứng với thuốc giảm đau (có đáp ứng, kém đáp ứng hoặc không đáp ứng dựa trên sự thay đổi điểm VAS của bệnh nhân), điểm ASIA.

Cận lâm sàng: Tổng số đốt xẹp, số đốt xẹp mới (giảm tín hiệu trên $T_{1}$, tăng tín hiêu trên $T_{2}$ ), số đốt xẹp cũ (giảm tín hiệu trên cả $T_{1}$ và $T_{2}$ ), vị trí đốt xẹp, đặc điểm hình thái theo phân loại Kanis, mức độ xẹp theo phân loại Genant, biến dạng cột sống (chia thành 2 nhóm có hoặc không, dựa trên số đo góc cobb trên 2 mặt phẳng coronal và sagittal so sánh với góc cobb bình thường theo tuổi $)^{4,5}$, đặc điểm đốt xẹp trên cắt lớp vi tính và cộng hưởng từ, mật độ xương cột sống tính theo T-score, vị trí XTĐS

2.6. Xử lý số liệu. Phân tích và xử lý số liệu trên phần mềm SPSS 20.0

\section{KẾT QUẢ NGHIÊN CỨU}

\section{1. Đăc điểm chung}

Bảng 3.1. Đặc điểm chung của đôî tượng nghiên cứu.

\begin{tabular}{|c|c|c|c|}
\hline \multicolumn{2}{|c|}{ Đă̆c điểm } & $\mathbf{N}$ & Tỷ lệ(\%) \\
\hline \multirow{3}{*}{$\begin{array}{c}\text { Giới } \\
\text { tính }\end{array}$} & Nam & 3 & 10.7 \\
\cline { 2 - 4 } & Nữ & 25 & 89.3 \\
\hline \multirow{4}{*}{ Tuổi } & Dưới 60 tuối & 5 & 17.9 \\
\cline { 2 - 4 } & Từ $60-70$ tuối & 7 & 25 \\
\cline { 2 - 4 } & Từ 71 đến 80 & 11 & $\mathbf{3 9 . 3}$ \\
\cline { 2 - 4 } & Từ 81 tuối trở lên & 5 & 17.9 \\
\cline { 2 - 4 } & Mean \pm SD & \multicolumn{2}{|c|}{$70.54 \pm 10.82$} \\
\cline { 2 - 4 } & Min - Max & \multicolumn{2}{|c|}{$44-86$} \\
\hline
\end{tabular}

Nhận xét: Có 25 BN nữ chiếm $89.3 \%, 3$ BN nam chiếm $10.7 \%$, tỷ lệ nữ/nam 8.35 . Tuổi trung bình 70.54, cao nhất là 86 tuổi, thấp nhất là 44 tuổi. Tỷ lệ nhóm tuổi cao nhất là từ 71 đến 80 tuổi $(39.9 \%)$.

\section{2. Đăc điểm lâm sàng}

Bảng 3.2: Đăc điểm về tiền sử của nhóm đôî tượng nghiên cứu

\begin{tabular}{|c|c|c|c|}
\hline \multicolumn{2}{|c|}{ Tiên sử liên quan } & $\mathbf{N}$ & $\begin{array}{c}\text { Tỷ lệ } \\
\text { \% }\end{array}$ \\
\hline $\begin{array}{c}\text { Hoàn cảnh } \\
\text { khởi phát }\end{array}$ & Chấn thương & 11 & 39.3 \\
\cline { 2 - 4 } & Tự nhiên & 17 & $\mathbf{6 0 . 7}$ \\
\hline \multirow{4}{*}{ Tiền sử bệnh } & Đái tháo đường & 1 & 3.6 \\
\cline { 2 - 4 } & Tăng huyết áp & 6 & 21.4 \\
\cline { 2 - 4 } & Cushing & 2 & 7.1 \\
\cline { 2 - 4 } & Bệnh tim mạch & 2 & 7.1 \\
\cline { 2 - 5 } & Bệnh hồ hấp & 2 & 7.1 \\
\hline
\end{tabular}




\begin{tabular}{|c|c|c|c|}
\hline \multirow{4}{*}{} & Cường giáp & 1 & 3.6 \\
\cline { 2 - 4 } & Bệnh khác & 5 & 17.9 \\
\cline { 2 - 4 } & Phối hợp & 3 & 10.7 \\
\cline { 2 - 4 } & Khỏe mạnh & 6 & 21.4 \\
\hline \multirow{2}{*}{$\begin{array}{c}\text { Nguyên nhân } \\
\text { loãng xương }\end{array}$} & Nguyên phát & 25 & $\mathbf{8 9 . 3}$ \\
\cline { 2 - 4 } & Thứ Phát & 3 & 10.7 \\
\hline
\end{tabular}

Nhận xét; Có 14.3 \% bệnh nhân tiên sử dùng thuốc corticoid, 4 BN tiên sử sử dụng corticoid (14.3\%). BN không có tiền sử chấn thương chiếm $60.7 \%$. Phân lớn BN đều mắc bệnh nền (78.6 \%), cao nhất tăng huyết áp chiếm $21.4 \%$. Loãng xương nguyên phát chiếm $89.3 \%$.

Bảng 3.3: Phân bố bệnh nhân theo triệu chứng lâm sàng.

\begin{tabular}{|l|l|l|}
\hline Diễn biến lâm sàng & $\mathbf{N}$ & Tỷ lệ (\%) \\
\hline
\end{tabular}

\begin{tabular}{|c|c|c|c|}
\hline \multirow{5}{*}{$\begin{array}{l}\text { Thời gian } \\
\text { diễn biến } \\
\text { bệnh }\end{array}$} & & & \\
\hline & Dưới 30 ngày & 7 & 25 \\
\hline & 31-60 ngày & 16 & 57.1 \\
\hline & 61-90 ngày & 5 & 17.9 \\
\hline & Trên 90 ngày & 0 & 0 \\
\hline \multirow{2}{*}{ Khởi phát } & Đột ngột & 28 & 100 \\
\hline & Từ từ tăng dân & 0 & 0 \\
\hline \multirow{2}{*}{$\begin{array}{c}\text { Đau tại } \\
\text { chố }\end{array}$} & $\hat{\mathrm{Am}} \mathrm{i}$ & 18 & 64.3 \\
\hline & Dữ dội & 10 & 35.7 \\
\hline \multirow{3}{*}{$\begin{array}{c}\text { Hạn chế } \\
\text { vận động } \\
\text { do đauu }\end{array}$} & Hạn chế đi lại & 7 & 25.0 \\
\hline & Không thể đứng & 12 & 42.9 \\
\hline & Không thể ngồi & 9 & 32.1 \\
\hline \multirow{2}{*}{$\begin{array}{c}\text { Hạn chế } \\
\text { hô hấp }\end{array}$} & Có & 2 & 7.1 \\
\hline & Không & 26 & 92.9 \\
\hline \multirow{2}{*}{ VAS } & Mean \pm SD & \multicolumn{2}{|c|}{$7.04 \pm 0.838$} \\
\hline & Min- Max & 6 & 9 \\
\hline \multirow{2}{*}{$\begin{array}{l}\text { Đáp ứng } \\
\text { giảm đau }\end{array}$} & Không đáp ứng & 6 & 21.4 \\
\hline & Kém đáp ứng & 22 & 78.6 \\
\hline
\end{tabular}

Nhânn xét: Tất cả các bệnh nhân khởi phát với đau đột ngột vị trí đốt xẹp, tăng khi vận động và giảm khi nghỉ ngơi. BN vào viện trong tình trạng đau âm î chiếm 64.3\%, 100\% bệnh nhân có hạn chễ vận động do đau. Thời gian diễn biến bệnh dưới 30 ngày chiếm 25\%, 31-60 ngày chiếm $57.1 \%, 61-90$ ngày chiếm $17.9 \%$. VAS trung bình 7.04 điểm.

\section{3. Đặc điểm cận lâm sàng}

Bảng 3.4: Mức độ loãng xương qua thang điểm T-Score đo ở cột sống

Điểm T-score

Mean \pm SD

$-3.89 \pm 0.99$

Min - Max

$(-2.5)-(-6.3)$

Nhận xét: Mật độ xương của đổi tượng nghiên cứu trung bình là -3.89 , Giá T-score thấp nhất là -6.3 , cao nhất là -2.5 .

Bảng 3.5. Đặc điểm XTĐS trên X-quang.

\begin{tabular}{|c|c|c|c|}
\hline \multicolumn{2}{|c|}{ Phân loại XTĐS } & $\begin{array}{c}\text { Số đốt xẹp } \\
(\mathbf{n = 1 3 2})\end{array}$ & $\begin{array}{c}\text { Tỷ lệ } \\
\text { \% }\end{array}$ \\
\hline Phân loại & Hình chêm & 68 & 51.5 \\
\hline
\end{tabular}

\begin{tabular}{|c|c|c|c|}
\hline \multirow[t]{2}{*}{ Kanis } & Lõm 2 mặt & 43 & 32.6 \\
\hline & $\begin{array}{c}\text { Lún ép thân } \\
\text { ĐS }\end{array}$ & 21 & 15.9 \\
\hline \multirow{3}{*}{$\begin{array}{c}\text { Phân loại } \\
\text { Genant }\end{array}$} & Nhẹ $20-25 \%$ & 49 & 37.1 \\
\hline & $\begin{array}{c}\text { Trung bình } 25 \\
40 \%\end{array}$ & 65 & 49.2 \\
\hline & Nặng >40\% & 18 & 13.7 \\
\hline & & $\begin{array}{l}\text { Số BN } \\
(n=28)\end{array}$ & $\begin{array}{l}\text { Tỷ lệ } \\
\text { \% }\end{array}$ \\
\hline \multirow{2}{*}{$\begin{array}{l}\text { Biến dạng } \\
\text { cột sổng }\end{array}$} & Có & 21 & 75 \\
\hline & Không & 7 & 25 \\
\hline
\end{tabular}

Nhận xét: XTĐS hình chêm chiếm phân lớn với $51.5 \%$, dạng lún ép thân đốt sống chiếm 15.9\%, Iõm 2 mặt chiếm 32.6\%. Xẹp trung bình (TB) chiếm tỷ lệ cao nhất 49.2\%, mức độ nhẹ $37.1 \%$, mức độ nặng chiếm 13.6\%.

Bảng 3.6: Đ̣ăc điểm XTĐS trên phim CLVT.

\begin{tabular}{|c|c|c|}
\hline $\begin{array}{c}\text { Tổn thương trên } \\
\text { CLVT }\end{array}$ & $\begin{array}{c}\text { Số đốt xẹp } \\
\text { (n = 132) }\end{array}$ & $\begin{array}{c}\text { Tỷ lệ } \\
\text { \%o }\end{array}$ \\
\hline XTĐS đơn thuân & 108 & 81.8 \\
\hline Hủy tường trước & 19 & 14.4 \\
\hline Hủy tường sau & 6 & 3.8 \\
\hline
\end{tabular}

Nhận xét: Có 19 đốt sống có hình ảnh hủy tường trước, 6 đốt sống có hình ảnh phá hủy tường sau lần lượt chiếm 14.4\%, 3.8\%

Bảng 3.7: Đặc điểm XTĐS trên phim MRI.

\begin{tabular}{|c|c|c|}
\hline Đặc điểm & $\begin{array}{c}\text { Số lượng đốt } \\
\text { sống }\end{array}$ & Tỷ lệ \% \\
\hline Xẹp cũ & 29 & 28.15 \\
\hline Xẹp mới & 103 & 71.85 \\
\hline Tống số & 132 & 100 \\
\hline $\begin{array}{c}\text { Số lượng } \\
\text { (n=103) }\end{array}$ & $\begin{array}{c}\text { Tỷ lệ } \\
\mathbf{( \% )}\end{array}$ \\
\hline $\begin{array}{c}\text { Đường rạn xương } \\
\text { trong ĐS }\end{array}$ & 29 & 28.2 \\
\hline Khí trong đốt sống & 6 & 5.8 \\
\hline Không bất thường & 68 & 66 \\
\hline
\end{tabular}

Nhânn xét: Trong tổng 132 đốt sống XTĐS, có 103 đốt sống xẹp mới chiếm 71.85\%.

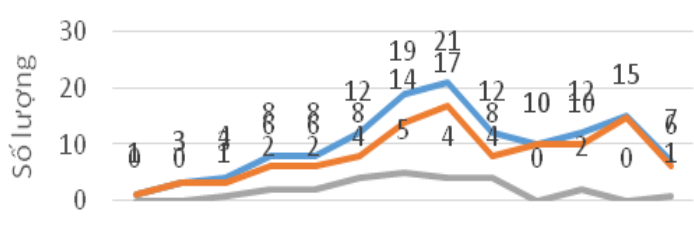

$\begin{array}{llllllllllllllllll}\text { T5 } & \text { T6 } & \text { T7 } & \text { T8 } & \text { T8 } & \text { T10 T11T12 L1 } & \text { L2 } & \text { L3 } & \text { L4 } & \text { L5 }\end{array}$

$$
\text { Axis Title }
$$

— tổng số —xẹp mới —xẹp ců

Biểu đồ 3.1: Phân bố vị trí XTĐS

Nhận xét: Vị trí xẹp nhiều nhất là T12 trong 
tổng số đốt xẹp và đốt mới xẹp là $T_{12}$ với 21 và 17 đốt sống. Trong các đốt sống xẹp cũ, xẹp nhiều nhất ở vị trí T11.

\section{BÀN LUÂN}

Nghiên cứu của chúng tôi được tiến hành trên $28 \mathrm{BN}$, trong đó có $3 \mathrm{BN}$ nam, $25 \mathrm{BN}$ nữ, tỷ lệ nữ/nam là 8.35 , tương đồng với nghiên cứu của Jan Van Meirhaghe ${ }^{6}$. Tuổi trung bình của BN là 70.5 , BN lớn tuổi nhất là 86 , nhỏ tuổi nhất là 44. Trong đó, nhóm BN từ 71-80 tuổi chiếm tỷ lệ cao nhất $39.3 \%$. Theo nghiên cứu của Đố Manh Hùng ${ }^{7}$ trên 79 bệnh nhân xẹp đốt sống thổng thường, tuổi trung bình là 66.5 nhóm tuổi 60-70 tuổi chiếm tỷ lệ cao nhất 34.3\%, như vậy nghiên cứu của chúng tôi độ tuổi trung bình và nhóm tuổi chiếm ưu thế đều cao hơn nhóm XTĐS thông thường. Trong nghiên cứu có 1 bệnh nhân nữ 44 tuổi xẹp đa tầng đốt sống do trên nên bênh nhân u tăng tiết ACTH lạc chỗ, với những bểnh nhân trẻ xuất hiện XTĐS do loãng xương cần lưu ý tìm kiếm nguyên nhân để điều trị căn nguyên bệnh. Trong nghiên cứu của chúng tôi, tất cả các $B N$ đều mắc các bệnh lý nền mạn tính, trong đó cao nhất là tăng huyết áp chiếm $21.4 \%$, phối hợp tăng huyêt áp, đái tháo đường chiếm $10.7 \%$, bệnh lý cường giáp, Cushing, tim mạch chiếm $7.1 \%$, cao hơn so với nghiên cứu của Đỗ Mạnh Hùng7 (bệnh khác chiếm 50.7\%). Cho thấy các $\mathrm{BN}$ XTĐS đa tầng thường mắc nhiều bệnh lý kèm theo, đây là yếu tố cần quan tâm trong việc lựa chọn chiến lược điều trị, trong can thiệp thủ thuật. Các bệnh lý như đái tháo đường, cường giáp, cushing thuộc nhóm bệnh gây loãng xương thứ phát ${ }^{8}$, vì vậy, ngoài việc điều trị tình trạng xẹp đốt sống loãng xương cần quan tâm điều trị các bệnh lý nền- căn nguyên gây loãng xương thứ phát. Phần lớn các $\mathrm{BN}$ XTĐS đơn thuần $(60.7 \%)$, còn lại $39.3 \%$ có yếu tố chấn thương nhưng đều là những chấn thương nhe như sau ngã ngồi từ ghế, vận động sai tư thế, kết quả tương tự nghiên cứu của Nguyễn Vũ.

Trong nhóm nghiên cứu, tất cả bênh nhân đều có triệu chứng đau tại chố tương ứng vị trí xẹp đối sống $(100 \%)$, đau khởi phát đột ngột (100\%), tăng lên khi vận động, giảm đi khi nghỉ ngời, hạn chế vận động do đau ở các mức độ khác nhau: hạn chế đi lại $25 \%$, không đứng (42.9\%), không ngồi (32.1\%), điểm VAS trung bình là 7.04, kết quả này tương tự với nghiên cứu của Đỗ Mạnh Hùng $^{7}$, của Daniela Alexandru ${ }^{2}$. Trong nghiên cứu của chúng tôi, thời gian diễn biến bệnh 31- 60 ngày chiếm tỷ lệ cao nhất $(57.1 \%)$, nghiên cứu của Jung-Hoon Lee ${ }^{9}$ thời gian diễn biến bệnh nhỏ hơn 7 ngày chiếm phần lớn $(47.5 \%)$, như vâyy ở nghiên cứu của chúng tôi thời gian diễn biến bệnh kéo dài hơn, do các bệnh nhân đa phần xẹp không có yếu tố chấn thương rõ ràng, đã trải qua thời gian điều trị nội khoa giảm đau nhưng kém hoặc không đáp ứng mới đến viện. Tất cả $B N$ có $A S I A ~ E$, không có dấu hiệu chèn ép thần kinh, phù hợp chỉ đinh bơm cement ${ }^{7}$.

Điểm T-score trung bình của nhóm -3.89, tương ứng kết quả nghiên cứu của Đỗ Mạnh Hùng7 T-score trung bình -3.9, cho thấy mức độ loãng xương cao ở nhóm BN XĐTCS, loãng xương nguyên phát chiếm tỷ lệ cao với $89.3 \%$. Theo tiêu chuẩn chẩn đoán loãng xương của WHO, tất cả các $B N$ thuộc nhóm đối tượng nghiên cứu đều là loãng xương rất nặng, chủ yếu là loãng xương nguyên phát mới phát hiên, điều đó phản ánh ý thức bệnh nhân về bệnh loãng chưa cao, và sự nguy hiểm của loã̃ng xương khi tiến triển âm thầm, khi biểu hiện ra triệu chứng đã ở giai đoạn nặng. Trên hình ảnh xquang, dựa vào phân loại Kanis có 3 nhóm chính: xẹp hình chêm chiếm tỷ lệ cao nhất $51.5 \%$, Iổm 2 mặt chiếm $32.6 \%$, lún ép thân đốt sống chiếm $15.9 \%$, tương đồng với nghiên cứu của Jung- Hoon Lee ${ }^{9}$, như vậy xẹp hình chêm hay gặp hơn cả. Theo phân loại Genant về mức độ xẹp thân đốt sống, xẹp trung bình thân đốt sống chiếm tỷ lệ $49.2 \%$, xẹp nhẹ chiếm $37.1 \%$, xẹp nặng chiếm $13.7 \%$, tương tự với kết quả nghiên cứu của Đố Mạnh Hùng7', mức độ xẹp trung bình chiếm tỷ lệ cao nhất. Trong nghiển cứu, tổn thương hủy tường sau có ở 6 đốt sống $(3.8 \%)$, các tổn thương này khó đánh giá trên hình ảnh $x$-quang, đa số tổn thương nằm trong nhóm bệnh nhân có yếu tố chấn thương kèm theo. Tỳ lệ tổn thương tường sau là $3.8 \%$, đốt sống tổn thương không có sự đẩy lồi tường sau, không có biểu hiện chèn ép thần kinh trên lâm sàng, nên vẫn có thể tiến hành bơm cement dạng tổn thương này cần lưu ý trong quá trình bơm cement, tránh để cement lan ra $1 / 3$ sau thân đốt sống, thông thương với đường vỡ, gây rò cement vào đốt sống. Trên hình ảnh cộng hưởng từ, đánh giá tổng cộng 132 đốt xẹp, trong đó có 103 đốt xẹp mới, 29 đốt xẹp cũ. Voormolen và cộng sự nghiên cứu 31 bệnh nhân bị XTĐS phù tủy xướng trên MRI, thấy mức độ giảm đau ở $97 \%$ sau cement 3 tháng $(p=0,01)$, cho thây việc sử dụng MRI là cần thiết để xác định chính xác đốt sống tổn thương cần can thiệp. Trong khi đó ở 14 bệnh nhân XTĐS không 
phù nề tủy xương thì tỷ lệ giảm đau chỉ chiếm $71 \%$. Vị trí XTĐS chủ yếu ở T11, T12, là vùng bản lề của cột sống phù hợp với nhiều nghiên cứu khác, do vùng bản lề (T11-L1) là nơi chuyển tiếp giữa cột sống ngực cố định và cột sống thắt lưng di động, cột sống vận động nhiều nên nguy cơ XTÐS tăng cao. Ngoài ra trên hình ảnh MRI chúng tôi đánh giá được hình ảnh đường rạn xương trong thân đốt sổng ở 29 đốt sống chiểm $28.2 \%$, khí trong đốt sống ở 6 đốt sống chiếm $5.8 \%$. Hình ảnh đường rạn xương trong đốt sống là 1 dấu hiệu gợi ý của bệnh lý hoại tử xương vô mạch do chấn thương (Bệnh lý Kummell), khí trong đốt sống ở những đốt sống XTĐS đơn thuần gợi ý tình trạng kém liền xương, do vậy cần nhanh chóng can thiệp điều trị cho bệnh nhân trong những trường hợp này để phòng tránh bệnh chuyển sang giai đoạn gãy xương không liền, nguy cơ dẫn đến các tổn thương thân kinh muộn.

\section{KẾT LUẬN}

Xẹp đa tầng cột sống ngực thắt lưng xảy ra chủ yếu ở bệnh nhân nữ giới, cao tuổi khởi phát sau một chấn thương nhẹ hoặc tự nhiên, thường đau kéo dài, tỷ lệ biến dạng cột sống, mức độ loãng xương và tỷ lệ bệnh nền cao. XĐTCS cần được đánh giá, điều trị sớm tránh tiến triển thành đau mạn tính. Ngoài điều trị tình trạng xẹp đốt sống cần quan tâm điều trị tình trạng loãng xương, điều trị các bênh lý nền gây loãng xương thứ phát nhằm hạn chế nguy cơ xẹp đốt sống.

\section{TÀI LIÊU THAM KHẢO}

1. Silverman SL. The clinical consequences of vertebral compression fracture. Bone. 1992/01/01/ 1992;13:S27-S31. https://doi.org/10.1016/8756-3282(92)90193-Z.

2. Alexandru D, So WJTPJ. Evaluation and management of vertebral compression fractures. 2012;16(4):46.

3. Zidan I, Fayed AA, Elwany AJJoKNS. Multilevel percutaneous vertebroplasty (more than three levels) in the management of osteoporotic fractures. 2018;61(6):700.

4. Abrisham SMJ, Ardekani MRS, Mzarch MAB. Evaluation of the Normal Range of Thoracic Kyphosis and Lumbar Lordosis Angles Using EOS Imaging. Maedica. Mar 2020;15(1):87-91. doi: 10.26574/maedica.2020.15.1.87.

5. Aebi M. The adult scoliosis. European Spine Journal. 2005/12/01 2005;14(10):925-948. doi: $10.1007 / \mathrm{s} 00586-005-1053-9$.

6. Van Meirhaeghe J, Bastian $L$, Boonen $S$ Ranstam J, Tillman JB, Wardlaw DJS. A randomized trial of balloon kyphoplasty and nonsurgical management for treating acute vertebral compression fractures: vertebral body kyphosis correction and surgical parameters. 2013;38(12):971.

7. Đố Manh Hùng. Nghiên cứu ứng dụng tạo hình đốt sổng bằng bơm cement có bóng cho bệnh nhân xẹp đốt sống do loãng xương. Đại học Y Hà Nôi; 2018.

8. Sổzen T, Özışık L, Başaran NÇ. An overview and management of osteoporosis. Eur J Rheumatol. 2017;4(1):46-56. doi: 10.5152/ eurjrheum.2016.048.

9. Lee J-H, Kwon J-T, Kim Y-B, Suk J-SJJoKNS. Segmental deformity correction after balloon kyphoplasty in the osteoporotic vertebral compression fracture. 2007;42(5):371.

\section{TỶ LÊ NHIỄ̂M HPV VÀ MỐI LIÊN QUAN ĐẾN CÁC BẤT THƯờNG TẾ BÀO CỔ TỬ CUNG Ở BỆNH NHÂN KHÁM PHỤ KHOA TẠI BỆNH VIỆN K}

\section{TÓM TẮT}

Mục tiêu: Xác định tỷ lệ nhiễm Human Papillomavirus (HPV) và nhận xét mối liên quan giữa nhiễm HPV nguy cơ cao (NCC) với các tổn thương bất thường tế bào cổ tử cung (CTC) ở những bệnh nhân (BN) đến khám phụ khoa tại bệnh viện K. Đối tượng và phương pháp: Nghiên cứu mô tả cắt ngang được tiến hành trên 2.194 BN đến khám phu khoa tai bênh viện $K$ từ tháng $1 / 5 / 2019$ đênn tháng 30/3/2020. Thu

\footnotetext{
${ }^{1}$ Bệnh viện $K$

2 Trường Đai hoc Y Hà Nôi

Chịu trách nhiệm chính: Trần Thị Thanh Thúy

Email: thanhthuy12913@gmail.com

Ngày nhận bài: 14.9.2021

Ngày phản biên khoa hoc: 27.10.2021

Ngày duyệt bài: 15.11.2021
}

Trần Thị Thanh Thúy ${ }^{1}$, Lê Văn Quảng1,2

thập số liệu qua khám, phỏng vấn BN và các kết quả xét nghiệm tữ hồ sơ khám bệnh. Kết quả: Trong tông số 2.194 BN có 295 trường hợp dương tính chiếm 13,4\%. Trong số ca nhiễm thì 12 type HPVNCC(khác type 16 , type 18 ) chiếm $72,9 \%$, chi nhiễm 1 type HPV16 là $13,6 \%$ và chỉ nhiếm 1 type HPV18 là $7,1 \%$. Có mối liên quan chăt chẽ giữa nguy cơ bất thường tế bào CTC, ung thư cổ tử cung liên quan với nhiễm HPV NCC, đăc biệt là 2 type HPV 16 và HPV $18(p<0,01)$ Kết luận: Tỷ lệ nhiễm HPV ở những $B N$ đến khám phụ khoa tại beệnh viện $\mathrm{K}$ trong mức độ trung bình.Việc xác định tỷ lệ nhiếm, định type HPV và mối liên quan đến các tổn thương bất thường tế bào CTC có vai trò quan trọng trong xác định nguy cơung thu cổ tử cung (UTCTC) để hướng dẫn các biện pháp phòng ngừa. cung.

Tư khóa: Human Papillomavirus, ung thư cổ tử 